\title{
INFLUÊNCIA DA TAXA DE DEFORMAÇÃO SOBRE O COMPORTAMENTO MECÂNICO EM TRAÇÃO DO AÇO INOXIDÁVEL DUPLEX UNS S32304*
}

\author{
Jéssica Dornelas Silva ${ }^{1}$ \\ Charles Henrique Xavier Magalhães² \\ Geraldo Lúcio de Faria ${ }^{3}$ \\ Leonardo Barbosa Godefroid"
}

\section{Resumo}

Diferentes mecanismos podem atuar e governar a deformação plástica de uma liga metálica. Estes mecanismos são fortemente dependentes de características como composição química, estrutura cristalina e energia de falha de empilhamento. Com o objetivo de se avaliar o comportamento do aço inoxidável duplex UNS S32304 quando submetido a esforços trativos e considerando a importância desta informação durante a conformação mecânica, este trabalho estudou a influência da taxa de deformação sobre as principais propriedades mecânicas medidas no ensaio de tração. Para a realização deste estudo, corpos de prova de tração foram usinados a partir de chapas do referido aço laminado a frio com espessura final de $2,5 \mathrm{~mm}$. Cada conjunto de 3 corpos de prova foi submetido às taxas de deformação de $7 \times 10^{-4} \mathrm{~s}^{-1}, 7 \times 10^{-3} \mathrm{~s}^{-1}$ e $4 \times 10^{-2} \mathrm{~s}^{-1}$. Por meio da análise dos resultados, observou-se uma diminuição na ductilidade e um aumento no limite de escoamento com o aumento da taxa de deformação. Entretanto, o limite de resistência não variou de forma significativa nas diferentes taxas estudadas.

Palavras-chave: Aço inoxidável duplex; Taxa de deformação; Comportamento mecânico.

\section{STRAIN RATE EFFECTS ON MECHANICAL BEHAVIOR IN TENSILE TEST OF UNS S32304 DUPLEX STAINLESS STEEL}

\section{Abstract}

Different mechanisms can act and control plastic strain in a metallic alloy. These mechanisms are strongly dependent of properties such as chemical composition, crystal structure and stacking fault energy. Aiming to evaluate the mechanical behavior of the UNS S32304 duplex stainless steel when subjected to tensile test, considering this information essential for successful forming processes, this work studied the influence of strain rate on the tensile properties of this alloy. For this purpose, tensile test specimens were machined from UNS S32304 cold rolled plates with the thickness of $2.5 \mathrm{~mm}$ and each group of 3 specimens was subjected to the strain rates: $7 \times 10^{-4} \mathrm{~s}^{-1}, 7 \times 10^{-3} \mathrm{~s}^{-1}$ e $4 \times 10^{-2} \mathrm{~s}^{-1}$. A decrease in ductility and an increase on the yield strength were observed with increasing strain rate. The tensile strength, however, did not vary significantly for the studied strain rates.

Keywords: Duplex stainless steel; Strain rate; Tensile properties.

\footnotetext{
Graduanda em Engenharia Metalúrgica. Departamento de Engenharia Metalúrgica e de Materiais (DEMET), EM, UFOP, Ouro Preto, MG, Brasil.

2 Mestrando em Engenharia de Materiais, REDEMAT, UFOP, Ouro Preto, MG, Brasil.

3 Físico. Dr. Professor. DEMET, EM, UFOP, MG, Brasil.

4 Engenheiro Metalúrgico. Dr. Professor. DEMET, EM, UFOP, Ouro Preto, MG, Brasil.
} 


\section{INTRODUÇÃO}

Aços inoxidáveis duplex são aços bifásicos cujas microestruturas consistem em frações aproximadamente iguais de ilhas de austenita em uma matriz ferrítica. Esses aços são caracterizados por uma combinação favorável das propriedades dos aços inoxidáveis ferríticos e austeníticos, apresentando elevada resistência mecânica, boa tenacidade, resistência à corrosão por pites, sob tensão e fadiga. Devido a estas propriedades, eles são amplamente aplicados em indústrias petrolíferas, de gás e química [1 - 4].

Durante o processamento dessas ligas, é necessário o balanceamento correto de elementos de liga para se obter uma composição química que possibilite, termodinamicamente, a existência das duas fases na proporção desejada à determinada temperatura. Além disso, é importante garantir o controle da temperatura e das taxas de resfriamento durante os processos de laminação a quente e no tratamento térmico de recozimento. Dessa forma, além de se ter condições cinéticas para a obtenção das frações de fases adequadas, é importante que não ocorra a precipitação de fases deletérias [1,3,5].

Como em todos os outros metais e ligas, as propriedades mecânicas do duplex dependem de fatores como o tamanho de grão, existência de bandeamento, grau de segregação e homogeneização da estrutura, entre outros. Porém, para analisar essas propriedades e seu comportamento sob tração, deve-se considerar também a influência das propriedades mecânicas específicas e dos mecanismos de deformação plástica de cada uma das fases constituintes, assim como a interação entre elas $[1,6,7]$.

Em geral, aços duplex possuem altos valores de limite de escoamento e de resistência mecânica, maiores do que a maior parte dos aços austeníticos ou ferríticos, enquanto mantém uma ductilidade relativamente elevada (acima de $25 \%$ à temperatura ambiente). Esses valores podem ser resultado de diversos mecanismos, como endurecimento por solução intersticial $(C, N)$ ou substitucional (Cr, Mo, Ni, etc.), refino de grão devido à presença de duas fases, ou tensão induzida pela diferença de contração das duas fases durante o resfriamento [1].

O mecanismo de deformação e o modo de distribuição das discordâncias nos grãos dependem fortemente da energia de falha de empilhamento (EFE). Na ferrita, que tem alta EFE, a deformação se dá principalmente pelo deslizamento de discordâncias, que tendem a se distribuir de maneira heterogênea e a formar células de discordâncias. Por outro lado, na austenita, que tem baixa EFE, as discordâncias tendem a se distribuir homogeneamente nos grãos e a dissociar-se, formando discordâncias parciais. Uma vez que as discordâncias parciais têm baixa mobilidade, para a acomodação da deformação, se desenvolvem maclas. Na fase austenítica, para valores menores de energia de falha de empilhamento, a deformação pode ocorrer também por transformação de fase induzida por deformação, e para valores maiores de energia de falha de empilhamento, pela movimentação de discordâncias $[6,8,9]$.

Os mecanismos de deformação dependem também, além de fatores intrínsecos como a anisotropia e a fração de fases, da taxa de deformação e da temperatura $[7,10]$. Fréchard et al. [11] investigaram mudanças durante o tracionamento de um duplex contendo $70 \%$ de austenita e $30 \%$ de ferrita e observaram, para altos níveis de deformação, linhas de deformação homogeneamente distribuídas na austenita e quase nenhuma deformação plástica visível na ferrita. Bahrami et al. [12] estudaram os efeitos da taxa de deformação na tenacidade à fratura da liga UNS S31803 e 
concluíram que a tenacidade diminui com a diminuição da taxa de deformação. Tsuchida et al. [13] analisaram os efeitos da temperatura e da taxa de deformação nas propriedades trativas da liga S32101, mostrando que, para esta liga, os limites de escoamento e resistência aumentam e a ductilidade diminui com o aumento da velocidade de deformação.

O UNS S32304 é um tipo de aço duplex que não contém adições significativas de molibdênio, pertencendo à família dos "lean duplex". O fenômeno de formação de martensita induzida por deformação pode ocorrer neste tipo de liga: a redução da quantidade de níquel e outros elementos gamagêneos aumenta a metaestabilidade da austenita [7].

Geralmente selecionado em função de sua resistência à corrosão aliada a boa resistência mecânica, a liga UNS S32304 tem uma ampla variedade de aplicações. A manufatura dos produtos para a maior parte das aplicações, segundo o IMOA [5], exige etapas de conformação relativamente simples como laminação de sessões cilíndricas e estampagem ou laminação de tampas de tanques e containers. Porém, como o limite de escoamento e o grau de encruamento deste material são relativamente altos, sua conformação exige elevados níveis de carregamento. Assim, em determinados processos, que são de maior complexidade na indústria metal-mecânica, a conformação sem deterioração das características mecânicas do aço é dificultada. Tendo em vista esta dificuldade, é importante se conhecer o comportamento do aço inoxidável duplex UNS S32304 quando submetido a esforços mecânicos. Neste contexto, este trabalho tem como objetivo estudar o efeito de diferentes taxas de deformação nas propriedades mecânicas da liga UNS S32304 quando submetida a esforços de tração.

\section{MATERIAIS E MÉTODOS}

O material objeto de estudo deste trabalho é o aço inoxidável duplex UNS 32304, produzido pela empresa Aperam South America, cuja composição química está apresentada na Tabela 1. Comparando-a com a especificação da norma ASTM A240/A240M, também fornecida pela empresa, é possível verificar que os valores encontram-se dentro das especificações.

Tabela 1. Composição química do aço UNS S32304 (\% em massa)

\begin{tabular}{|ccccccccccc|}
\hline Elemento & $\mathrm{C}$ & $\mathrm{Mn}$ & $\mathrm{Si}$ & $\mathrm{Cr}$ & $\mathrm{Ni}$ & $\mathrm{P}$ & $\mathrm{S}$ & $\mathrm{Cu}$ & $\mathrm{Mo}$ & $\mathrm{N}$ \\
\hline$\%$ & 0,01 & 1,34 & 0,31 & 22,23 & 4,10 & 0,025 & 0,0004 & 0,09 & 0,32 & 0,10 \\
\hline
\end{tabular}

Tabela 2. Especificação química do aço UNS S32304, segundo a norma ASTM A240/A240M (\% em massa)

\begin{tabular}{|ccccccccccc|}
\hline Elemento & $\mathrm{C}_{\text {Max }}$ & $\mathrm{Mn}$ & $\mathrm{Si}_{\text {Max }}$ & $\mathrm{Cr}$ & $\mathrm{Ni}$ & $\mathrm{P}_{\text {Max }}$ & $\mathrm{S}_{\text {Max }}$ & $\mathrm{Cu}$ & $\mathrm{Mo}$ & $\mathrm{N}$ \\
\hline$\%$ & 0,03 & 2,00 & 1,00 & 22,00 & 3,5 & 0,035 & 0,015 & 0,10 & 0,1 & 0,05 \\
& & & & 24,00 & 5,5 & & & 0,60 & 0,6 & 0,2 \\
\hline
\end{tabular}

Amostras para confecção de corpos de prova (CP's) de tração (Figura 1), com dimensões baseadas na norma ASTM E8/E8M[14], foram retiradas de uma chapa laminada a frio com redução de área de $48 \%$, recozida e decapada com acabamento 2B (laminador de encruamento). Uma amostra $10 \mathrm{~mm} \times 10 \mathrm{~mm} \times 2,5 \mathrm{~mm}$, foi retirada da 
chapa para análise da microestrutura inicial via MO Leica DM2700M. A superfície analisada foi o plano da espessura da chapa no sentido de laminação.

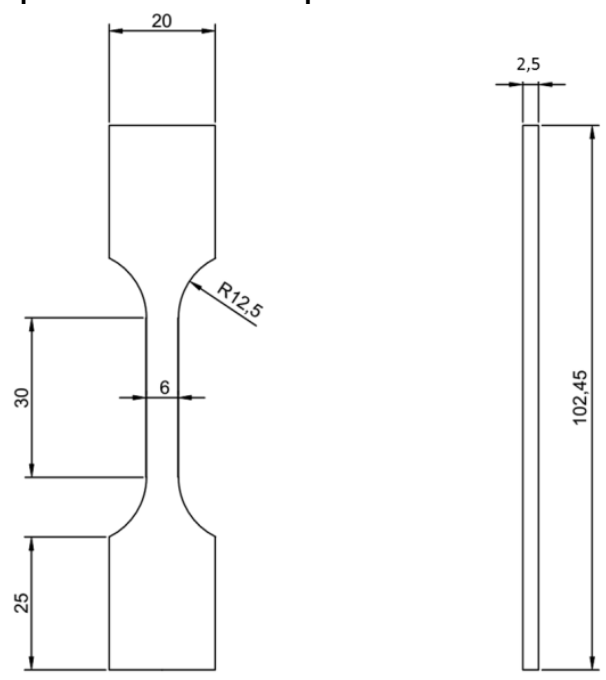

Figura 1. Vista frontal e lateral do modelo para confecção dos CPs reduzidos de tração. Dimensões em milímetros.

Para análise da microestrutura no microscópio óptico e medição de fases, a amostra foi embutida e preparada metalograficamente, seguindo os procedimentos da Norma ASTM E3-01[15], fazendo uso de suspensão aquosa de alumina de $1 \mu \mathrm{m}$, pasta de diamente de $1 \mu \mathrm{m}$ e pasta de diamente de $0,25 \mu \mathrm{m}$ na etapa de polimento. $\mathrm{O}$ ataque químico foi realizado utilizando-se o reativo Behara $(80 \mathrm{ml}$ de água destilada, $40 \mathrm{ml}$ de ácido clorídrico, $4,8 \mathrm{~g}$ de bifluoreto de amônio e $1 \mathrm{~g}$ de metabissulfito de potássio). A medição da fração de fases foi realizada no $\mathrm{MO}$ equipado com um software analisador de imagens, utilizando-se um aumento de 1000x em vários campos obtendo-se a média aritmética pelo método das áreas de metalografia quantitativa.

$\mathrm{Na}$ superfície da chapa, foram realizados ensaios de dureza Rockwell $\mathrm{A}$, fazendo-se cinco medidas aleatórias na amostra e tomando-se a média.

Para análise do comportamento mecânico da liga, foram feitos, na máquina servo hidráulica MTS, ensaios de tração completos com diferentes taxas de deformação: $7 \times 10^{-4} \mathrm{~s}^{-1}, 7 \times 10^{-3} \mathrm{~s}^{-1}$ e $4 \times 10^{-2} \mathrm{~s}^{-1}$. Para cada taxa, foram utilizados três corpos de prova e uma média foi tomada para análise dos resultados. Com o auxílio de um microscópio eletrônico de varredura, foram feitas análises fractográficas na superfície fraturada dos corpos de prova ensaiados e análise microestrutural da estrutura deformada.

\section{RESULTADOS E DISCUSSÃO}

\subsection{Análise Microestrutural do Estado de Entrega}

A partir da análise da microestrutura do estado de entrega, observou-se uma estrutura bandeada formada por lamelas de austenita em uma matriz ferrítica com grãos alongados no sentido da laminação, conforme apresentado na Figura 2. 


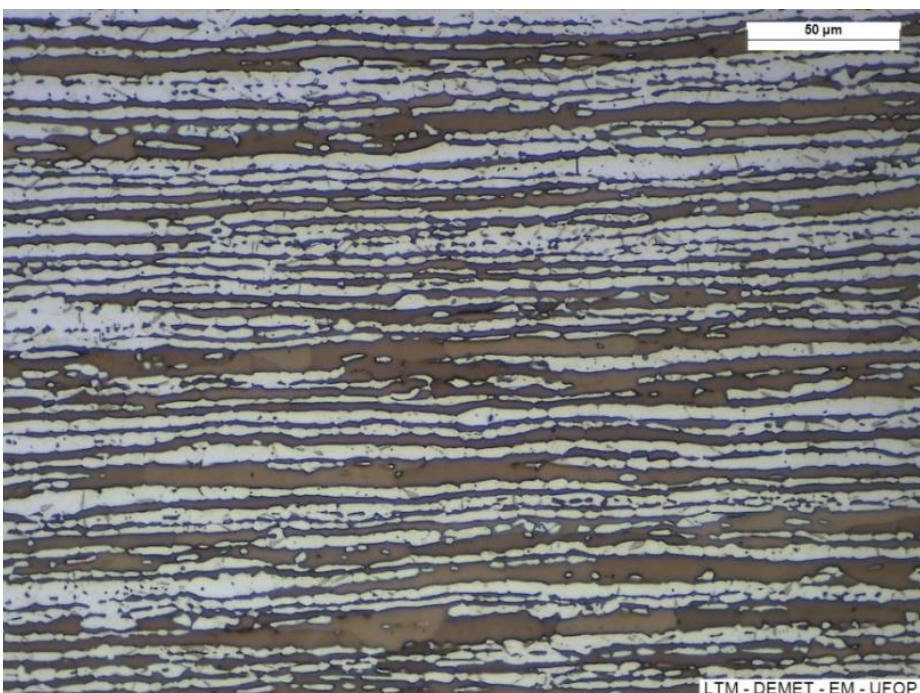

Figura 2. Microestrutura do aço UNS S32304 no estado de entrega. MO - 500x - Ataque Behara II.

Observou-se também que a microestrutura é refinada, sendo esta característica uma consequência do alto grau de redução experimentado no processo de laminação a frio. Sabe-se que o tamanho de grão de uma estrutura de aço inoxidável duplex recozida depende fortemente do grau de deformação prévio e menos da temperatura de recozimento [16].

$\mathrm{Na}$ Figura 3, estão evidenciados os diferentes tipos de ferrita destacados por Choi et al [17]: em (1) tem-se uma ferrita fina com morfologia acicular nas interfaces de maclas de recozimento da austenita e em (2), tem-se a ferrita formada a partir dessas maclas, na forma de grãos alongados no sentido da laminação. Esse tipo de nucleação ocorre pelo fato dessas regiões macladas serem regiões de alta energia, se tornando sítios propícios para a formação de ferrita a partir da austenita durante o recozimento. O tipo de estrutura em (3), segundo Choi, está associado à nucleação e crescimento de austenita em contornos de grãos ferríticos durante a transformação de fases ferrita-austenita em altas temperaturas.

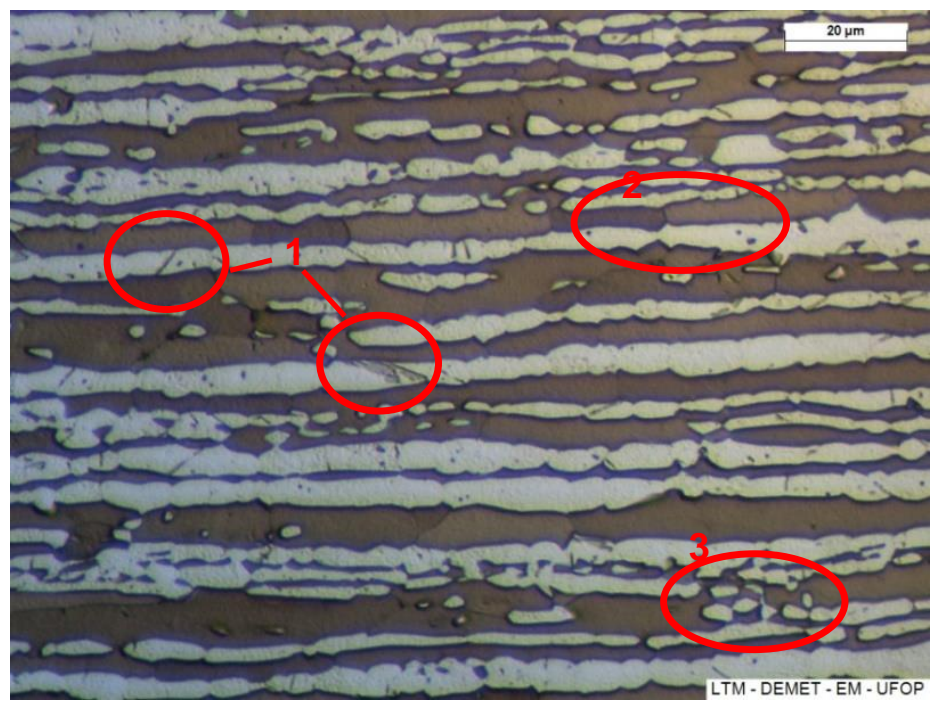

Figura 3. Diferentes tipos de ferrita na estrutura: (1) acicular, (2) grãos grandes e alongados (morfologia majoritária da ferrita) e (3) nucleação e crescimento de austenita em contornos de grãos de ferrita. MO - 1000x. Ataque Behara II. 


\subsection{Ensaio de Dureza no Estado de Entrega}

A dureza média obtida para o aço UNS S32304 no estado de entrega foi 58HRA.

Tabela 3. Resultados de dureza Rockwell A realizados no estado de entrega do aço UNS S32304

\begin{tabular}{|cc|}
\hline Medidas & $\begin{array}{c}\text { Medida da dureza } \\
\text { em Rockwell A }\end{array}$ \\
\hline 1 & HR $_{\mathbf{A}}$ \\
\hline 2 & 57 \\
\hline 3 & 58 \\
\hline 4 & 57 \\
\hline 5 & 60 \\
\hline Média & 60 \\
\hline Desvio Padrão & $\mathbf{5 8}$ \\
\hline
\end{tabular}

\subsection{Medição da Fração de Fases}

$\mathrm{Na}$ medição de fração volumétrica de fases por meio da aplicação do método das áreas de metalografia quantitativa obteve-se $55 \pm 5 \%$ de ferrita e $45 \pm 5 \%$ de austenita. Considerando o desvio padrão, esta proporção está dentro dos padrões da serie duplex 2304, que geralmente estão em torno de $50 \%$ de cada fase [1].

\subsection{Ensaio de Tração}

As curvas médias obtidas no ensaio de tração estão apresentadas na Figura 4. É possível observar que, quando submetida a diferentes taxas de deformação, o aço estudado se comporta de formas diferentes, apresentando valores diferentes de limite de escoamento, resistência e deformação total.

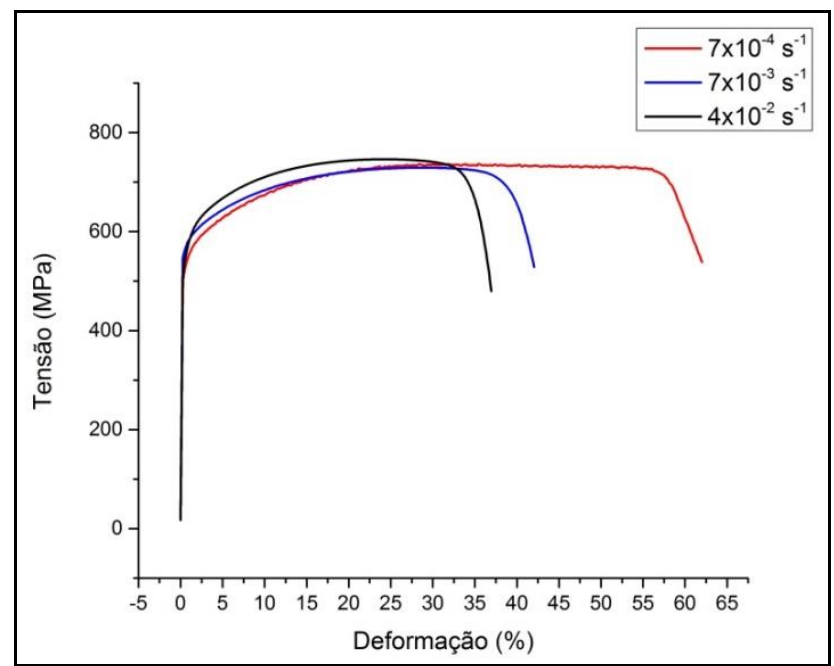

Figura 4 - Curvas $\sigma \times \varepsilon$ obtidas nos ensaios de tração do aço UNS S32304 submetido a diferentes taxas de deformação.

A propriedade que mostrou maior variação quando o material é submetido a diferentes velocidades de deformação foi a ductilidade. Observa-se que quanto maior é a taxa de deformação, menor é a deformação total experimentada pelo aço estudado (Figura 5). A diminuição da ductilidade com o aumento da taxa de 
deformação também foi observada por Tsuchida et al [13] em um estudo desenvolvido para o aço UNS S32101. Isso ocorre porque sob menores taxas de deformação, as discordâncias se movimentam com menor velocidade, diminuindo o nível interação entre si, favorecendo assim a deformação plástica e proporcionando um maior alongamento da estrutura. Para taxas de deformação maiores, as discordâncias se movimentam com maior velocidade e interagem entre si mais intensamente, promovendo uma concorrência pela migração de planos de deslizamento, restringindo assim a deformação plástica e resultando em uma condição de menor ductilidade [18].

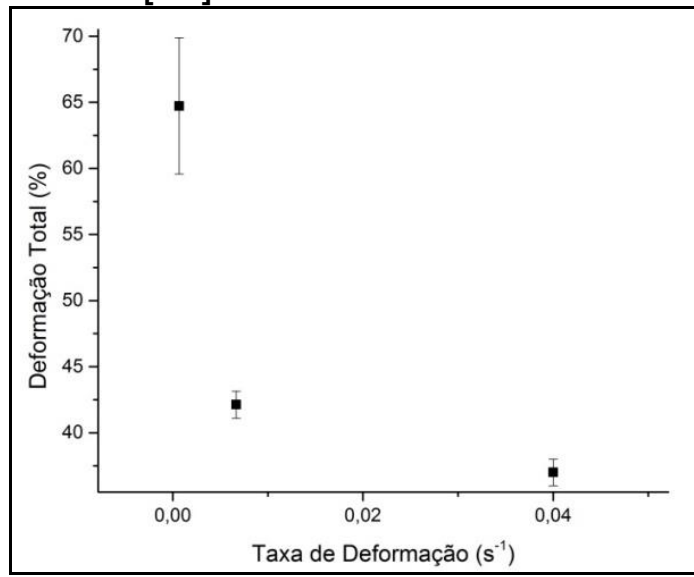

Figura 5 - Variação da ductilidade do aço UNS S32304 em função da taxa de deformação.

Considerando-se os desvios experimentais, observa-se que há pouca diferença nos limites de resistência medidos para as diferentes taxas de deformação (Figura 6-a), mostrando que, para o aço estudado, esta propriedade é pouco dependente da velocidade de deformação nas taxas estudadas. Lemos [19], em seu trabalho sobre o efeito da taxa de deformação em um aço SAE 4340, notou que o limite de resistência aumentou com o aumento da velocidade de deformação, o que ocorreu devido a um maior empilhamento de discordâncias e consequente encruamento para maiores taxas. No presente estudo, isso pode não ter ocorrido para o aço UNS S32304 devido ao fato de sua estrutura ser originalmente muito refinada. Neste caso, mesmo sob baixas taxas de deformação, a mobilidade das discordâncias já seria limitada pela elevada densidade de contornos de grão.

Já o limite de escoamento (Figura 6-b) cresceu com o aumento da taxa de deformação. Este efeito, que também foi notado por Nordberg[20], se deve ao fato de que sob taxas de deformações mais elevadas, a mobilidade atômica é reduzida e, assim, o material oferece maior resistência ao escoamento. De acordo com Dieter [18], conforme foi verificado neste estudo, é esperado que o limite de escoamento seja mais afetado pela variação da taxa de deformação do que o limite de resistência. 

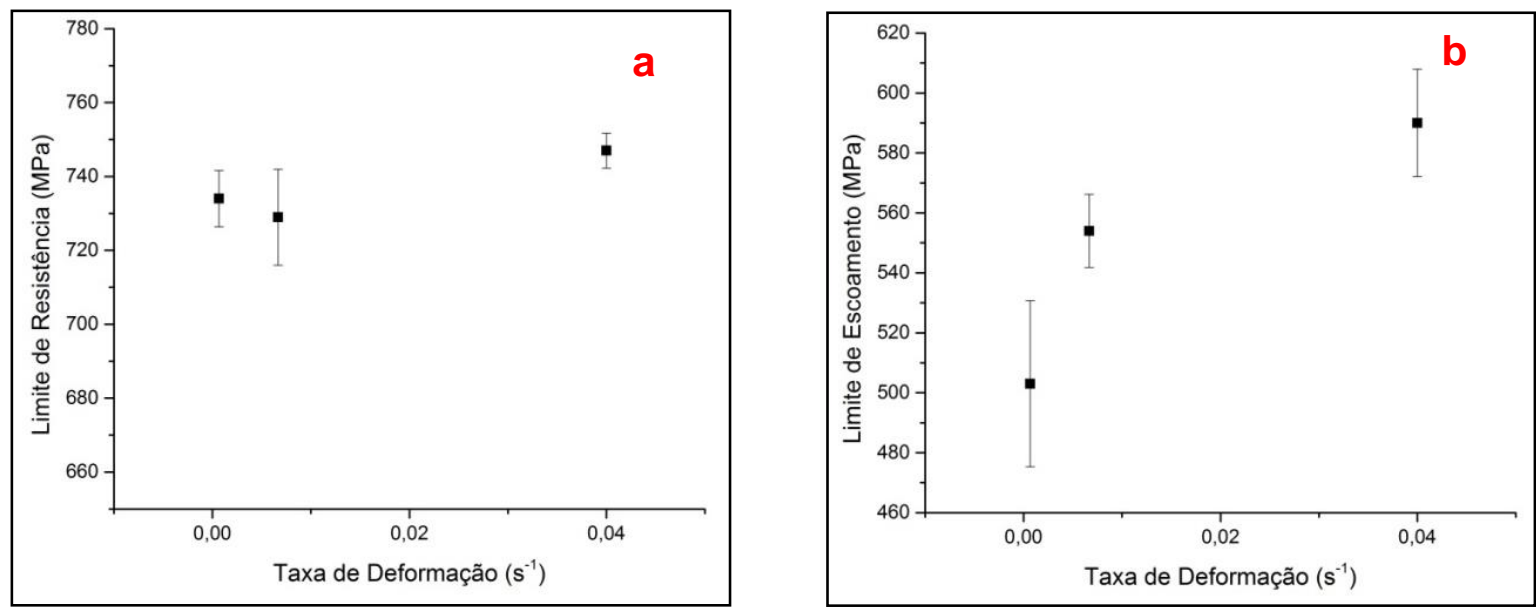

Figura 6. Variação do (a) limite de resistência e (b) limite de escoamento do aço UNS S32304 em função da taxa de deformação.

Deve-se destacar que para as taxas de deformação estudadas, pode haver uma variação de até $100 \mathrm{MPa}$ no limite de escoamento do material. Esta variação é muito significativa, principalmente quando se leva em consideração possíveis processos de conformação mecânica do aço UNS S32304.

Para elevadas taxas de deformação os níveis de carregamento do maquinário de conformação deverão ser significativamente maiores, o que pode acarretar em maior desgaste dos mesmos. Além desta observação, como não há variação significativa do limite de resistência com o aumento da taxa de deformação, para velocidades mais altas, haverá menor diferença entre limite de escoamento e limite de resistência do material, o que implicará uma região de deformação plástica uniforme menor. Neste contexto, microcavidades tenderão a nuclear na estrutura do material para menores valores de deformação plástica, aumentando assim as chances de aparecimento de defeitos volumétricos na estrutura do material durante a conformação, ou em caso extremo, acelerando o colapso final do material.

\subsection{Análises Fractográficas}

A análise dos corpos de prova de tração fraturados no MEV mostrou que a fratura, em todos os casos, foi dúctil, sendo caracterizada pela presença de dimples (Figura 7). A amostra que foi submetida à maior taxa de deformação (Figura 7-c), apresentou dimples menores quando comparada às outras duas. Isto se deve ao fato de que para maiores taxas de deformação, a razão elástica (LE/LR) aumenta, uma vez que, conforme visto no item 3.4, o limite de escoamento aumenta mais do que o limite de resistência com o aumento da taxa de deformação. O aumento da razão elástica resulta em uma diminuição na capacidade de encruamento uniforme do material e o processo de nucleação de microcavidades (dimples) é favorecido. Se mais dimples são formados, eles coalescem rapidamente entre si, o que leva à formação de trincas, não havendo tempo para o seu crescimento e resultando em um comportamento menos dúctil. 

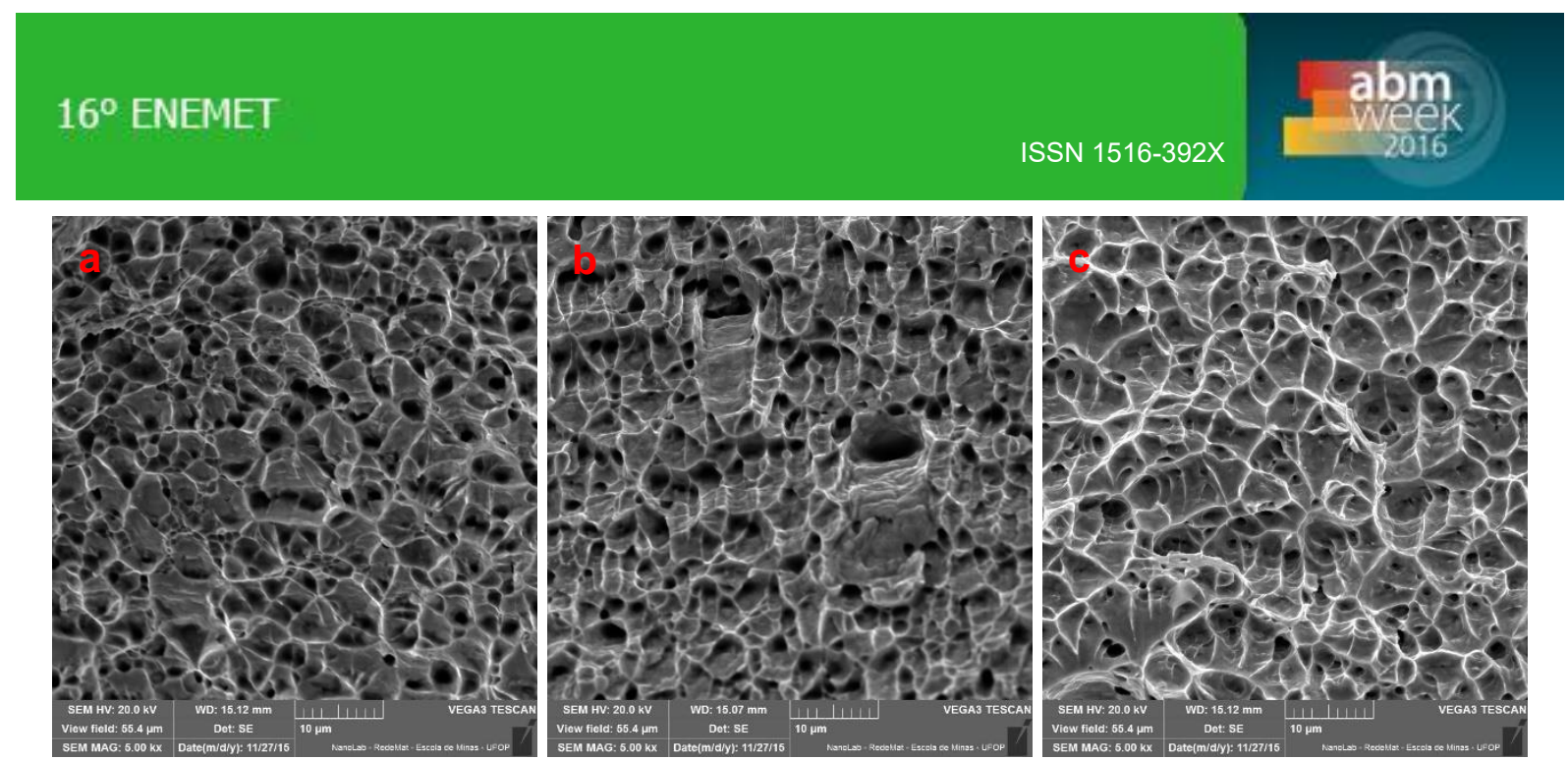

Figura 7 - Análise fractográfica - MEV 5000x -

(a) $7 \times 10^{-4} \mathrm{~s}^{-1}$

(b) $7 \times 10^{-3} \mathrm{~s}^{-1}$ e (c) $4 \times 10^{-2} \mathrm{~s}^{-1}$.

As amostras tracionadas nas três velocidades de deformação estudadas foram amostradas na região da instabilidade plástica (empescoçamento) e foram submetidas a análises microestruturais em um microscópio eletrônico de varredura. A Figura 8 apresenta os resultados obtidos.

Pode-se observar que as microestruturas dos corpos de prova deformados são ainda mais refinadas do que a inicial. Isto se deve à deformação experimentada pelo material durante o ensaio. Na análise microestrutural, procurava-se encontrar sinais de deformação plástica como bandas de cisalhamento, maclas ou martensita induzida por deformação. Como não foi possível esta observação no MO devido ao refinamento dos grãos, a análise da microestrutura precisou ser realizada com 0 auxílio de um MEV. Porém, ainda assim, não foi observada nenhuma alteração microestrutural além do refinamento e alongamento da estrutura. Em geral, as microestruturas resultantes das três taxas de deformação foram semelhantes.

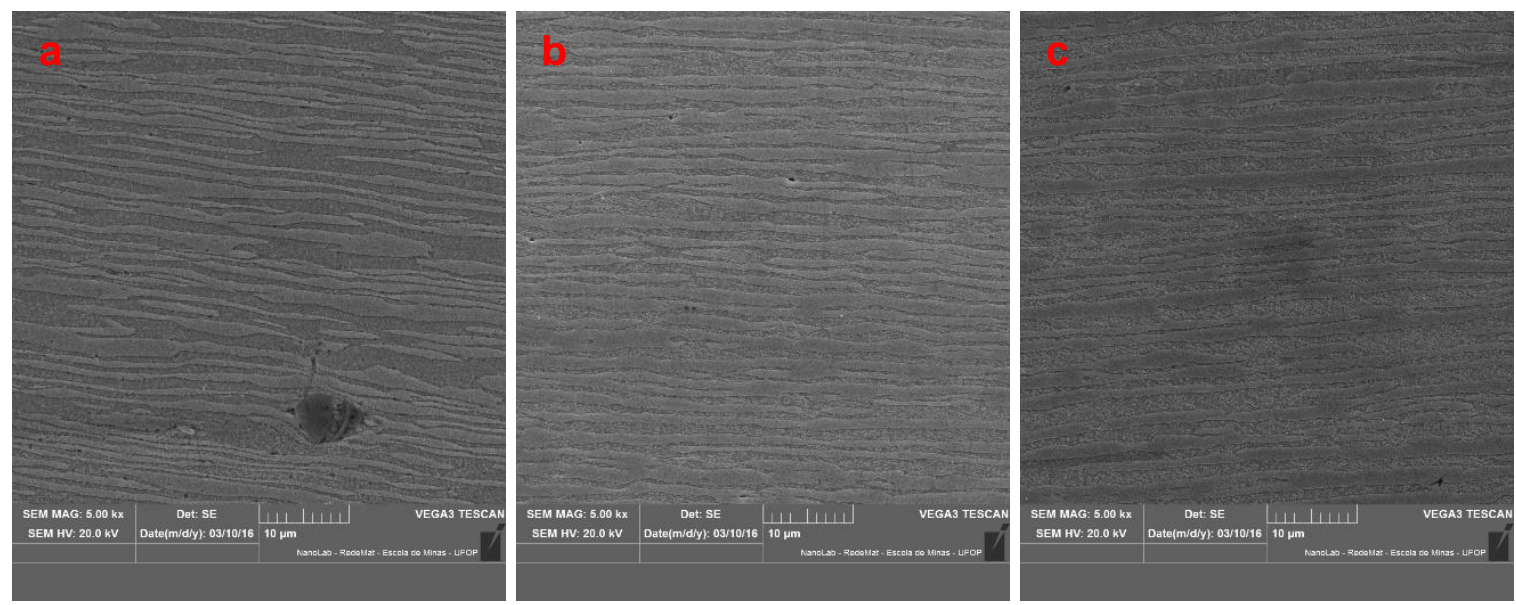

Figura 8 - Micrografia da microestrutura final obtida dos ensaios de tração a (a) $7 \times 10^{-4} \mathrm{~s}^{-1}$, (b) $7 \times 10^{-3} \mathrm{~s}^{-1}$ e (c) $4 \times 10^{-2} \mathrm{~s}^{-1}$. MEV - 5000x.

\section{CONCLUSÃo}

As frações volumétricas das fases austenita e ferrita do aço, assim como a dureza, se encontravam conforme os padrões estabelecidos pela empresa.

A fratura observada foi de natureza dúctil nos três casos, com grande quantidade de dimples. A microestrutura inicial foi ainda mais refinada nos ensaios de tração, não sendo possível verificar outras alterações microestruturais, como bandas de 
cisalhamento, maclação ou formação de martensítica induzida por deformação, mesmo com o auxílio de um MEV.

A taxa de deformação influenciou fortemente a deformação total e o limite de escoamento da liga. A ductilidade decresceu e o limite de escoamento cresceu com o aumento da taxa de deformação. Já o limite de resistência, no caso do aço utilizado, mostrou pouca dependência da taxa de deformação nos ensaios realizados. Estes resultados mostram que um aumento na taxa de deformação resulta em maior dificuldade durante a conformação, uma vez que maiores esforços serão necessários e o campo de deformação será menor, acelerando o surgimento de defeitos durante o processo.

Dessa forma, o controle da taxa de deformação é um parâmetro muito importante na conformação do aço inoxidável duplex UNS S32304, pois esta resulta em uma mudança no comportamento durante a deformação plástica do material.

\section{Agradecimentos}

Os autores agradecem ao CNPq pelo auxílio financeiro, à empresa Aperam South America por conceder amostras do material de estudo, aos laboratórios Nanolab/REDEMAT, Ensaios Mecânicos e LTM - DEMET/UFOP.

\section{REFERÊNCIAS}

1 Gunn, R. N. Duplex Stainless Steels - Microstruture, properties and applications. Cambridge, Inglaterra. Abington publishing, 2003.

2 Silva, A. L. V. C.; Mei, P. R. Aços e Ligas Especiais. $3^{a}$ edição. São Paulo; Editora Blucher; 2010.

3 Colpaert, H. Metalografia dos produtos siderúrgicos comuns. 4⿳亠丷a edição. São Paulo; Editora Blucher; 2008.

4 Gonçalves, K. A. M. B.; Oliveira, T. R.; Santos, D. B. Textura Cristalográfica e propriedades mecânicas dos aços inoxidáveis duplex UNS S31803 e UNS S32304 após a laminação a frio e recozimento. Contribuição técnica ao $12^{\circ}$ Seminário Brasileiro do Aço Inoxidável - ABM Week, Rio de Janeiro, 2015.

5 Practical Guidelines for the Fabrication of Duplex Stainless Steel. $3^{a}$ edição. Londres, UK. International Molybdenum Association, 2014.

6 Jeong, C. U.; Heo, Y.-U.; Choi, J.Y; Woo, W.; Choi, S. -H. A study on the micromechanical behaviors of duplex stainless steel under uniaxial tension using ex-situ experimentation and the crystal plasticity finite element method. International Journal of Plasticity. 2015; 75: 22-38.

7 Gauss, C. Evolução microestrutural do aço inoxidável duplex UNS S32205 durante a laminação a frio e posterior recozimento. Dissertação de mestrado, Universidade de São Paulo. Lorena; 2015.

8 Reick, W.; Pohl, M.; Padilha, A. F. Recrystallization-transformation combined reactions during annealing of a cold rolled ferritic-austenitic duplex stainless steel. ISIJ International. 1998; 38(6): 567-51.

9 Arthuso, E. C. M. Influencia da taxa de deformação e da temperatura na ductilidade a quente do aço inoxidável duplex UNS 32304. Dissertação de mestrado, Universidade Federal de Minas Gerais. Belo Horizonte; 2013.

10 Kruger, L.; Schwarz, F; Martin, U.; Roven, H. -J. Strain rate and temperature effects of the flow behavior and microstructure of X2CrNiMoN22-5-3 duplex stainless steel. Materials Science \& Engineering A. 2014; 592: 6-11. 
11 Frechard, S.; Martin, F.; Clément, C.; Cousty, J. AFM and EBSD combined studies of plastic deformation in a duplex stainless steel. Materials Science \& Engineering $A$. 2006; 418 (1-2): 312-319

12 Bahrami, A.; Bourgeon, A.; Cheaitani, M. Effects of strain rate and microstructure on fracture toughness of duplex stainless steels under hydrogen charging conditions.

13 Tsuchida, N.; Kawahata, T.; Ishimaru, E. Takahashi, A. Effects of temperature and strain rate on tensile properties of a lean duplex stainless steel. ISIJ International. 2014; 54 (8): 1971-1977.

14 ASTM E8/E8M-11, Standard test methods for tension testing of metallic materials, ASTM International, West Conshohocken, PA, 2001.

15 ASTM E3-11, Standard Guide for Preparation of Metallographic Specimens, ASTM International, West Conshohocken, PA, 2011

16 Silvério, V. A. Estudo da evolução do tamanho de grão na laminação a quente de barras de aço médio carbono microligado ao vanádio - 38MnSiV5. Dissertação de mestrado, Escola Politécnitica da Universidade de São Paulo. São Paulo; 2008.

17 Choi, J. Y.; Ji, J. H.; Hwang, S. W.; Park, K. -T. Strain induced martensitic transformation of Fe-20Cr-5Mn-0,2Ni duplex strainless steel during cold rolling: effects of nitrogen addition. Materials Science and Engineering A. 2011; 528: 6012-6019.

18 Dieter, G. E. Mechanical metallurgy. McGraw-Hill book company, 1961.

19 Lemos, G. V. B.; Vieira, D. M. M.; Santos, B. P.; Haag, J.; Costa, V. M.; Meinhardt, C. P.; Fabrício, D. A. K.; Chiossi, T. P.; Strohaecker, T. R. O efeito da velocidade de deformação no ensaio de tração de um aço SAE 4340. Contribuição técnica ao 68응 Congresso Anual da ABM - Internacional. Belo Horizonte, 2013.

20 Nordberg, $\mathrm{H}$. Note on the sensitivity of stainless steels to strain rate. AvestaPolarit Research Foundation and Sfeffield Hallam University. Research Report No 04.0-1, 2014. 